\title{
LA HISTORIA DE LO IMAGINARIO: TEMAS, PROBLEMAS Y PERSPECTIVAS
}

Fernando Rosas Moscoso

Universidad Ricardo Palma

\begin{abstract}
RESUMEN
La historia de lo imaginario es una de las tendencias actuales de la investigación histórica. Estudia el imaginario colectivo, que es el conjunto de representaciones que se ubican fuera del conocimiento y la experiencia de una sociedad. Necesita de una visión interdisciplinaria y se va modificando al paso del tiempo. Las etapas de la Historia Universal, desde la Antigüedad Clásica hasta el presente, definen diversas perspectivas de imaginarios colectivos. Utiliza instrumentos científicos de análisis y enfrenta problemas concretos. El presente artículo concluye con la mención a importantes hitos bibliográficos y a una revisión de la historia de lo imaginario en el Perú.
\end{abstract}

\section{PALABRAS CLAVE}

Historia / Imaginario / Psicología / Ficción / Realidad

\begin{abstract}
The history of imagination is one of the new fields in the historical research. It is a study of the collective imagination which is the system of representations that stay out of the knowledge and experiences of a society. It needs an interdisciplinary vision and changes as time change. The Universal History from the Antiquity to the present time shows many manifestations of collective imagination. It uses a scientific analysis and faces concrete problems. The paper shows also a reference of the principal bibliography and develops the history of imagination in Peru.
\end{abstract}

\section{KEY WORDS}

History / Imagination / Psicology / Fiction / Reality 
La historia de lo imaginario es una de las tendencias actuales de investigación histórica que alcanzó desarrollo a partir de los años 70' del siglo XX; acompañó el surgimiento de la historia de las mentalidades y de la historia de la marginalidad entre otras, pero sin llegar a tener la difusión que esas otras dos tendencias tuvieron. Sin embargo, los orígenes de la preocupación por el tema de lo imaginario en la historia son anteriores a esa década y se refleja en muchas obras dispersas y que responden a inquietudes individuales de historiadores o incluso antropólogos, psicólogos y otros científicos sociales.

\section{ASPECTOS TEÓRICOS}

El ser humano posee la capacidad de imaginar y ella lo ha acompañado a lo largo de todo su proceso histórico y a través de múltiples manifestaciones referidas a aspectos de su existencia. La imaginación aflora como mecanismo de compensación frente a limitaciones y carencias o también como muestra de una creatividad reflejada por aspiraciones o deseos de carácter individual o colectivo. Como objeto de estudio de la historia el imaginario colectivo es el que centra su análisis y proyecciones, ya que el imaginario individual escapa a los objetivos de su investigación.

Sobre la definición de la historia de lo imaginario, consideramos que la propuesta de Evelyn Patlagean es la que refleja mejor sus alcances, ella señala: "El dominio de lo imaginario está constituido por el conjunto de representaciones, que desbordan el límite que definen los alcances de la experiencia y los encadenamientos deductivos que ellos permiten" (Patlagean, 1978, p. 249). El concepto de representaciones es fundamental para conocer la naturaleza de las expresiones de lo imaginario, así como la mención a la experiencia, en sus múltiples manifestaciones señala el límite a partir del cual se expresan dichas representaciones. A esa definición se puede agregar el hecho de que cada sociedad tiene un imaginario y que dicha expresión define una intensa dinámica de cambios, ya que los límites entre lo real y lo imaginario sufren transformaciones a lo largo del tiempo, convirtiéndose en determinado momento algo imaginario en real como algo real deviene en imaginario.

Está íntimamente ligada a la dinámica de lo imaginario una mecánica de opuestos, en donde juegan diversos términos como por ejemplo la vida y la muerte, el deseo y la represión, la evasión o el refugio, la alegría y 
la desesperación, la justicia y la injusticia, y tantos otros. Asimismo, como contextos de afloración se tienen al espacio y al tiempo, elementos que estimulan o revierten las funciones de ese imaginario.

Como se ha señalado, a la historia le interesa el imaginario colectivo, por ser expresión de un consenso o de una mayoría en una sociedad y en un tiempo determinado. Por otra parte, dentro de una visión sistémica ese imaginario está vinculado a las estructuras fundamentales de la vida del hombre en sociedad, que son las económicas, las políticas, las sociales y las mentales; siempre considerando que estos elementos estructurales no son compartimientos estancos, sino que al conformar un todo, se integran alimentando desplazamientos que los involucran entre sí; así por ejemplo un imaginario económico tiene implicancias en el imaginario social y viceversa.

La manera de aproximarse al estudio de lo imaginario desde la perspectiva de la historia exige una visión interdisciplinaria por las distintas manifestaciones que presenta, lo cual acerca esa visión histórica a otras ciencias sociales.

\section{TEMAS DE LA HISTORIA DE LO IMAGINARIO}

A lo largo del desarrollo de la historia de la civilización se pueden encontrar una enorme variedad de temas que están involucrados con lo imaginario. Desde las civilizaciones antiguas y a través de evidencias arqueológicas se pueden perfilar aspectos de su vida a través de objetos, inscripciones y monumentos, pudiéndose establecer por ejemplo, el imaginario egipcio en relación a la muerte o las representaciones del mal en el mundo sumerio. Pero es a partir de la antigüedad clásica y especialmente en relación al mundo griego, cuando encontramos las primeras manifestaciones de un prolífico imaginario colectivo relacionado con mitos y leyendas, monstruos o pacíficos dioses benefactores que completan los espacios ignotos o concretan los temores de su momento. Los héroes y las leyendas complementan la vida de la sociedad griega, integrando un mundo desconocido, pero entendido como real a las condiciones de su presente. Roma sigue por ese camino, pero enriquecida por su inmensa expansión, las manifestaciones de lo imaginario romano desbordan la simple reproducción del griego y penetran físicamente en lejanos contextos o solo por referencias, para poblarlos con especies naturales desconocidas o seres casi humanos. 
La aparición del cristianismo amplía las extensiones del imaginario colectivo con la incorporación de sus propios elementos representativos vinculados a sus elementos característicos que se expresan fuera de la realidad. La imagen de la salvación puebla de imágenes y esperanzas a gentes sumidas en las confusiones y proyecciones de los primeros tiempos; ya más adelante, con la existencia de un cristianismo universal, se estabilizan las formas y manifestaciones de lo imaginario, reflejándose ello en un nuevo orden, en donde las expresiones de ese cristianismo toman cuerpo y se consolidan. Los miedos persisten, las manifestaciones se hacen cada vez más numerosas y el cristianismo triunfante vence a las fuerzas del mal en una guerra santa que enaltece ante los ojos de Dios la fuerza y valentía de los hombres. Grandes construcciones reflejan un imaginario colectivo que incluye una fauna fantástica y un paraíso rico en imágenes. Se construyen así verdaderos mundos imaginarios, en donde se reflejan las limitaciones y los temores de sociedades en crecimiento. Lo maravilloso es uno de los elementos que emerge con fuerza durante esta época, implicando una transformación de aspectos críticos o discutidos de la vida en sociedad, tales como el hambre, la desnudez, el sexo, la lucha por la supervivencia y otros; transfiere estas inquietudes a tierras lejanas y desconocidas, a paraísos en la tierra o a posibles infiernos, transformando en sueños expresiones de una realidad llena de angustias y necesidades. Lo maravilloso, inicialmente criticado por la iglesia, se incorpora a la vida cotidiana de las gentes derivando en múltiples expresiones que rondan lo fantasmagórico o lo tremendo o excesivo. Finalmente, se produce una lenta desintegración de lo maravilloso a consecuencia de la acción de la iglesia que lo canaliza al milagro, de la ciencia que lo pone en duda y, finalmente, de la misma historia que empieza a mostrar desde el siglo XV necesidad del dato preciso (Rosas Moscoso, 1988, p. 35).

Las crisis alimentan los imaginarios colectivos, así, después de un gran proceso de expansión, en donde nace el sistema capitalista, se llega a la crisis del siglo XIV de exaltación y temor frente a los flagelos que caracterizan el siglo, sean las enfermedades como la Peste Negra o las revueltas y la guerra. Pasados esos flagelos, el nacimiento de un nuevo orden enriquece nuevamente el mundo, alejando a las gentes de la temática de la muerte o del apocalipsis y del combate entre santos y demonios, así se pasa de las grandes catedrales góticas con sus gárgolas y fauna fantástica a un mundo en donde el hombre ocupa el centro del universo y lo modela y explota con su capacidad, ingenio y sabiduría. 
El salto expresivo de ese imaginario colectivo puede encontrarse en las pinturas del Bosco y su proyección posterior, en la producción artística de Rafael, Leonardo y Miguel Ángel. Así, el historiador va encontrando la huella que dejan las sociedades a través de sus expresiones imaginarias, en donde el proceso de humanización característico de la época moderna encierra también una riqueza enorme en aspectos imaginarios. En otras palabras, el Humanismo y el Renacimiento no hacen desaparecer el rico imaginario medieval, sino más bien lo enriquecen y transforman; la muerte es el tema de siempre, pero también aparece la obsesión por el tiempo, la exaltación de la belleza y las típicas representaciones del mal, con sus infiernos, demonios y monstruos. Nuevos temas cobran fuerza, la locura y la brujería destacan en su generosa expresividad. La herejía va desapareciendo como arma del maligno, pero con las nuevas manifestaciones de la reforma religiosa va alcanzando otros niveles de expresión. Con los ánimos religiosos y espirituales exacerbados, los imaginarios colectivos se van enriqueciendo hasta llegar al siglo XVIII, en donde con las luces de la razón anteriores formas de imaginario se van retirando y refugiando en los ángulos más oscuros de las mentalidades colectivas de su tiempo. Sin embargo, la razón no impide que la imaginación vuele, pues siguen gravitando antiguos temores y siguen existiendo tierras desconocidas, así como también la cotidiana violencia y las múltiples expresiones de la desigualdad y la injusticia.

Con la aparición de la Revolución Industrial, el imaginario colectivo del occidente asume nuevas manifestaciones, pues la introducción de máquinas, artefactos y avances científicos en general, generan un contraste con las limitaciones preexistentes, donde la gente todavía muere de hambre o padecen grandes limitaciones de todo tipo. El progreso de la ciencia y la tecnología nos permite procesar nuevas manifestaciones de lo imaginario, de la cuales las obras de Julio Verne serían la mejor expresión.

El siglo XX define nuevos canales de proyección en la imaginación, siendo algunos de ellos el cine que permite concretar nuevas expresiones de lo imaginario, o la tecnología de la navegación aérea y espacial que abre las puertas a la imaginación extraterrestre con sus poderosas civilizaciones destructoras o también sus indefensas manifestaciones, como E.T.; pero los héroes de la antigüedad también están de vuelta, pues Superman, Acuaman, Batman y Robin y tantos otros, no son más que la continuidad de los antiguos héroes griegos. Algunos aspectos se cierran, tales como los espacios desconocidos que alimentaron una fauna fantástica; hoy el planeta está recorrido de punta a punta, pero eso no impide que las imágenes de grandes 
cataclismos o el fin de la vida del hombre en la tierra formen parte de un nuevo imaginario. Toda sociedad en todo momento genera un conjunto de representaciones imaginarias, por lo tanto nuestra época y el presente que hoy vivimos no carece de imaginario colectivo, pues la misma búsqueda de un mundo perfecto y justo no es más que un ejercicio de imaginación, como también el éxito, la riqueza y el poder, al que los hombres de nuestros días rinden culto.

Recorriendo la historia, a cada paso nos encontramos con muestras claras de un rico imaginario colectivo, que al compás del paso del tiempo va desprendiéndose de ciertas imágenes y asimilando otras, o también rectificando y enriqueciendo antiguas y persistentes expresiones. Lo imaginario acompañará siempre a las sociedades por más que el conocimiento avance y que la tecnología permita una cada vez mayor comprensión y conocimiento de la realidad.

\section{INSTRUMENTOS DE ANÁLISIS}

Si bien, todas las expresiones materiales y espirituales de la vida del hombre en sociedad constituyen instrumentos o herramientas para la comprensión de los procesos históricos, existen algunas herramientas teóricas y metodológicas que propician el tratamiento de los aspectos vinculados a la historia de lo imaginario. Dentro de estas herramientas podemos mencionar las siguientes:

- La iconografía: las manifestaciones pictóricas, escultóricas o arquitectónicas permiten una aproximación a un imaginario tangible, que permite explorar la génesis y las expresiones evolucionadas que encierran esas manifestaciones materiales. No interesa necesariamente el plano estético, dentro o fuera de los planos de belleza establecidos, sino más bien interesa la lectura que se pueden sacar de dichas manifestaciones en tanto expresiones alejadas de la realidad, pero que en su momento podían entenderse incluso como reales. Los estudios iconográficos nos permiten detectar expresiones narrativas o singularidades que reflejan los temores, angustias o debilidades del hombre en un momento determinado. La lectura iconográfica encierra un doble nivel de expresión, uno interno referido a la posible interpretación que se tenga de la manifestación específica y uno externo que se nutre de la mera descripción del elemento sujeto a análisis. 
Al presente se han agregado otras manifestaciones que se vinculan y reflejan los procesos del imaginario colectivo, por ejemplo, la fotografía, el cine, las instalaciones, el video y demás expresiones de la vida contemporánea. En ese sentido, el discurso expuesto debe ser coherente con la naturaleza del elemento proyector y expresivo.

- La perspectiva interdisciplinaria: como se ha señalado, la historia de lo imaginario requiere de una fina y consistente perspectiva interdisciplinaria que permitiría un mejor conocimiento de las múltiples expresiones de lo imaginario y de su entorno; además de los estudios psicológicos, propios de la naturaleza de su objeto de estudio, otros elementos pueden ser traídos a colación tales como aquellos económicos, sociales, políticos o incluso vinculados a los fenómenos de la naturaleza. La mirada que permite ver mejor las expresiones de los imaginarios colectivos a través de la historia, es una mirada interdisciplinaria, sin ella se compromete el verdadero conocimiento y reconocimiento de los objetos de estudio.

- Las expresiones orales: sin la concretización propia de las imágenes, la oralidad constituye un rico filón para el estudio de la historia de lo imaginario. Relatos, tradiciones, leyendas y otras expresiones recogidas por una oralidad supérstite, enriquecen los escenarios de la historia de lo imaginario. Por su naturaleza, dichos elementos requieren de una metodología especial que reconoce el paso del tiempo y los cambios inherentes a él, pero que contribuye al mejor conocimiento de la materia.

- La historia de larga duración: como aproximación metodológica, la perspectiva de larga duración visualiza mejor la dinámica de las transformaciones o cambios en la historia de lo imaginario. De lo que se trata es de abordar un escenario o tema a través del mayor tiempo o duración posible para lograr así tener una clara visión de los cambios que sufre el imaginario colectivo en su desarrollo; por ejemplo, el miedo a la muerte puede generar un enorme conjunto de expresiones que al paso del tiempo van desapareciendo o retornando según sean las condiciones en las que se desenvuelve la sociedad humana, esas expresiones de la muerte pueden ser exacerbadas por las crisis o más adelante se pueden diluir bajo el impulso del desarrollo científico y tecnológico, volviéndose una figura pálida o gaseosa, perdiendo así su atributo grotesco o espantoso, para reencontrarse nuevamente con otros aspectos negativos, al compás de nuevas carencias o amenazas. 
- El análisis del discurso: el estudio del discurso puede también a través de conceptos o términos reiterados constantemente o a través del uso de palabras que encierran mensajes posibles de ser catalogados como expresiones de un imaginario colectivo, constituir el día de hoy una herramienta usada para lograr la comprensión de dicho imaginario. La semiótica, en ese sentido, nos da los instrumentos metodológicos para explorar los discursos y extraer las expresiones de un imaginario colectivo concreto.

Los intereses que expresan mentalidades colectivas en las sociedades van variando con el pasar del tiempo, pasando de representar a un mundo natural y concreto a otro sobrenatural y ficticio. Pero bien sabemos que en este escenario la realidad se transforma en ficción como la ficción en realidad.

\section{PROBLEMAS}

El estudio de la historia de lo imaginario se enfrenta permanentemente a determinados obstáculos o problemas que requieren de las siguientes perspectivas metodológicas para superarlos:

a) Definir la pertinencia de los elementos estudiados, reafirmando claramente su carácter imaginario.

b) Mantener siempre presente el verdadero sentido de lo imaginario, pues a través del anacronismo podemos trasplantar limitaciones o visiones inherentes a nuestro tiempo, al objeto de estudio sujeto a análisis. Se debe perfilar perfectamente el carácter de imaginario en el objeto de análisis y conservarlo a lo largo de la duración del estudio.

c) Avanzar en la identificación de las fuentes para su estudio, tales como el análisis iconográfico, el aplicado al cine, al folclore y a la oralidad, entre otros.

d) Reforzar permanentemente la interdisciplinaridad como un medio imprescindible para lograr el mayor conocimiento de lo imaginario.

e) Identificar con precisión los límites en el espacio y en el tiempo, que se fijan al estudio de lo imaginario.

f) Identificar las diferentes lecturas de lo imaginario, estableciendo sus aspectos internos y externos. 


\section{HITOS BIBLIOGRÁFICOS}

Hacer una selección de trabajos que podrían representar una tendencia actual de investigación histórica, siempre estará sujeta a discusión y observaciones, sin embargo, es necesario mostrar algunos de ellos para poder descubrir los espacios concretos que favorecen una mayor producción o los íconos representativos de la bibliografía en ese campo. La historia de lo imaginario tiene también trabajos señeros y campos en donde se acentúa el flujo de producción.

Tomando en cuenta la evolución de los procesos históricos, la Antigüedad clásica se convierte en un escenario favorable a través del estudio de su mitología, sus rituales y sus temores colectivos; en ese sentido, los trabajos de Pierre Vidal Naquet y Jean Pierre Vernant representan un aporte importante. Una interesante observación acerca de la muerte en Grecia, la encontramos en la obra de Emily Vermeule.

En el caso de la Edad Media, existen dos campos de trabajo destacados, por un lado las manifestaciones del arte medieval como expresión de imaginario, en donde destacan los aportes de Henry Focillon y Georges Duby, por otra parte, el estudio de un mundo fantástico representada por los trabajos de Jurgis Baltrusaitis, quien se introduce en las expresiones más puntuales, en donde emerge un conjunto de representaciones fantásticas, impregnadas de influencias ultramarinas y en constante incremento. El medioevo también acerca al tema del demonio y de otras manifestaciones del mal; dentro de ese campo y como uno de los pioneros destaca la figura de Arturo Graf y la producción más reciente de Claude Kappler. Claude Lecouteux se mueve fluidamente entre el estudio de los monstruos y fantasmas; no se puede olvidar los aportes al imaginario medieval de Jacques Le Goff, quien aborda temas de imaginario que van desde la aparición de la idea de purgatorio hasta el imaginario asociado a los espacios lejanos y desconocidos. El mismo Marc Bloch a través de su obra Los reyes taumaturgos, hace observaciones consistentes al campo de lo imaginario.

Bajo el impacto de la peste negra en el siglo XIV, se inician las manifestaciones propias de los tiempos modernos, en donde el tema de la muerte se impone como manifestación de un dinámico imaginario colectivo. No se puede olvidar el aporte precursor de Johannes Huizinga, con su conocida obra El otoño de la Edad Media. El sentido de la muerte y del amor también abre nuevas perspectivas y en esos campos destacan los trabajos de Alberto Tenenti. La brujería, antigua conocida emerge con fuerza dentro de la bi- 
bliografía del imaginario; en ese sentido, se puede considerar que Julio Caro Baroja, desde nuestra lengua proyecta estudios consistentes en ese campo, uniéndose a él Robert Mandrou y Robert Muchembled. El tema de la brujería aborda numerosos sub temas que a su vez constituyen materia de investigación puntual, tales como los aspectos sexuales, los rituales, la extirpación de la brujería, la posesión maligna, entre otros. Por otra parte, Lucien Febvre define los rasgos del imaginario del XVI en El problema de la incredulidad en el siglo XVI. La religión de Rabelais. Por último, debemos hacer referencia a la obra de Michele de Certau La fable mystique 1. XVI-XVII siecles, brillante expresión de la historia de lo imaginario.

Con el Siglo de las Luces, la Revolución Industrial y las Revoluciones Burguesas, el imaginario como tema de investigación histórica aparentemente define un retroceso, pero no es así, ya que los viejos temas se mantienen y aparecen otros nuevos, tales como un nuevo imaginario en relación a los cuentos y las leyendas, con figuras que emergen de un contexto rural y poco conocido que todavía se resiste a desaparecer. Las mismas ciudades con su oscuridad nocturna y sus peligros, dan pie a la aparición de un inquietante imaginario representado por monstruos urbanos o asesinos que sobrepasan las dimensiones de lo cotidiano. En el espacio, las tierras desconocidas son cada vez más escasas, sin embargo, todavía sobrevive el deseo de encontrar en ellas monstruos que más impresionan por el tamaño que por sus extrañas formas; en ese sentido, una ballena o un calamar gigantes trae consigo el recuerdo de los antiguos monstruos marinos que poblaban el Atlántico y el Índico.

El siglo XIX, con sus avances tecnológicos permite la creación de un nuevo imaginario que estaría representado por máquinas de un poder insospechado, como el submarino que navega las profundidades oceánicas o el cohete que permite la llegada a la luna, y es la novela la que aproxima a las gentes a ese nuevo imaginario y Julio Verne se constituye en el mejor de sus representantes. El estudio sistemático de ese imaginario producto del desarrollo científico y tecnológico todavía espera mayores aportes. Por otra parte, la presencia de las masas y su acción en los diversos campos de la vida del hombre en sociedad crea nuevos imaginarios, y también la locura, en donde Michel Foucault hace un gran aporte y nuevas revelaciones aunque sea un tema antiguo.

El siglo XX nos presenta también nuevos campos de análisis; décadas antes el cine ya había empezado a crear espacios de ficción y a posibilitar 
una materialización de contenidos imaginados y que en los últimos tiempos ha sido objeto de estudio por historiadores como Marc Ferro, y si bien no es historiador Edgar Morin en su trabajo El cinema o el Hombre Imaginario. Ensayo de Antropología Sociológica, hace un aporte muy importante. La lectura de las imágenes cinematográficas descubre varios discursos que se alimentan de una doble y fluctuante naturaleza constituida por la realidad y la ficción. La proliferación de héroes con super poderes también es parte, como se ha señalado, de una profusa producción del imaginario colectivo y también es materia de análisis por algunos historiadores, en donde destaca el estudio de Michel Vovelle sobre la "Mujer Maravilla".

Debemos notar que la producción bibliográfica en la historia de lo imaginario presenta una fuerte tendencia a los estudios referidos a la Edad Media y a la Época Moderna, disminuyendo su número a partir del siglo XIX. Sin embargo, algunos historiadores trabajan el último siglo con destreza, combinando diversos temas y analizando la producción de reconocidos intelectuales de formación no histórica, pero que llegan a destacar en el campo de la historia de lo imaginario; el mejor ejemplo lo encontramos en la obra de Michel de Certau Histoire et psychanalyse entre science et fiction, que reúne parte de su producción dispersa en varias publicaciones.

Queda la incógnita sobre si el hombre está perdiendo su imaginación o si la imaginación en sus múltiples manifestaciones, ya no es un aspecto preponderante en su vida.

\section{LA HISTORIA DE LO IMAGINARIO EN EL PERÚ}

Lamentablemente, en el Perú no se ha desarrollado esta nueva tendencia de investigación histórica, ya que si bien existen algunos aportes puntuales en ese campo, no constituyen realmente una tendencia de investigación autónoma. Es más fácil encontrar los aportes de antropólogos, arqueólogos, sociólogos o incluso psicólogos, que trabajos de historiadores; esta situación quizás es producto de la mayor facilidad con que se desenvuelven esos científicos sociales en el campo de lo inter y multidisciplinario. También puede explicar esta situación la ausencia de cursos sobre esta tendencia en los currículos universitarios de la especialidad de historia, para entender mejor lo señalado, basta recordar que recién hace muy pocos años se han introducido cursos de Historia de las Mentalidades, la cual tuvo su nacimiento paralelamente a la Historia de lo Imaginario. 
Sin embargo, cabe hacer un recuento de los aportes en el campo que nos ocupa, para así tener una visión de las áreas que han sido trabajadas por unos pocos historiadores y varios científicos sociales, procedentes de otros campos de las ciencias humanas. Una primera mención lo tiene el pasado prehispánico, donde arqueólogos como Anne Marie Hocquenghem en sus estudios sobre la iconografía mochica, así como Federico Kauffmann, quien se ha ocupado en varias oportunidades sobre el tema de la muerte y la religiosidad prehispánica. El caso del incanato se refleja en perspectivas presentadas por Wilfredo Kapsoli, Franklin Pease y Marco Curátola. Una aproximación distinta a los anteriores aportes la hace Marcos Yauri Montero al analizar el simbolismo de las plantas alimenticias nativas en el imaginario andino.

El impacto de la llegada de los españoles constituye un tema fértil para las investigaciones del imaginario colectivo del siglo XVI y sus proyecciones posteriores, que llegan incluso al presente; en este campo destaca la producción de Luis Millones, quien es el que navega con más soltura en el imaginario a través de varias obras importantes, tales como Poder y religión en los Andes centrales, con Wilfredo Kapsoli La memoria de los ancestros, y en una intensa relación con destacados psicoanalistas ha generado trabajos colectivos como El retorno de las huacas y otros más. Un historiador que también se acerca a estos temas es Lorenzo Huertas Vallejos.

En el campo de la historia del virreinato, existe un trabajo que refleja lo más representativo de la historia de lo imaginario y es la obra de Ramón Mujica Pinilla Ángeles apócrifos en la América Virreinal; el cual tiene su contraparte en la contribución de la historiadora boliviana del arte Teresa Gisbert, con su importante obra El paraíso de los Pájaros Parlantes. La imagen del otro en la cultura andina. Luis Miguel Glave en De Rosa y espinas. Economía, sociedad y mentalidades andinas. Siglo XVII, también ofrece acercamientos al imaginario colectivo de esa época. Quizás los dos mejores aportes a una historia de lo imaginario de larga duración nacen de las investigaciones realizadas por Alberto Flores Galindo y Manuel Burga; el primero en Buscando un inca, recorre, al compás de las supervivencias andinas ancestrales, un largo trecho de la historia peruana con proyecciones incluso a lo contemporáneo; el segundo, en su Nacimiento de una utopía. Muerte y resurrección de los incas, realiza la misma investigación, pero con referencias más concretas al proceso histórico, pasando del folclor a las instituciones virreinales y viceversa. Es evidente que la formación francesa de ambos historiadores les haya permitido entrar en contacto con las mani- 
festaciones de la historia de lo imaginario ya existentes en Francia, lo que les posibilitó plasmar en sus investigaciones los elementos representativos de dicha nueva tendencia de investigación.

En otro terreno, El miedo en el Perú, editado y compilado por Claudia Rosas Lauro, ofrece en varias contribuciones acercamientos al tema del imaginario; es indudable que los temores alimentan la imaginación colectiva, por lo que se puede acercar al tema desde la perspectiva de otra tendencia de investigación que es la Historia de las Mentalidades. Hay que reconocer la estrecha relación que existe entre esa tendencia, la historia de lo imaginario y la historia de la marginalidad, compartiendo las tres la presencia permanente de la psicología, como elemento generador. Es por ello que se atisba también imaginario en las otras dos obras colectivas publicadas por Claudia Rosas y que son El Odio y el perdón en la Historia del Perú y La Marginación en el Perú. Siglos XVI-XXI; estos tres trabajos reflejan la coexistencia de las tres tendencias de investigación mencionadas.

Aunque no pertenecen como temas a la historia del Perú, conviene mencionar el aporte de José Antonio del Busto en su Historia de los descubrimientos geográficos, libro elaborado en base a un curso que se dio en la Pontificia Universidad Católica durante unos pocos años, en los que presenta con detalle las manifestaciones del imaginario europeo entre el medioevo y el mundo moderno frente a los espacios desconocidos. El autor de este artículo también incursionó en el campo de la historia de lo imaginario al publicar en 1988, El Hombre y el Dominio de los Espacios: Mecanismos Oníricos y Temores en la Expansión Europea. Siglos XIII-XV, en donde partiendo de un análisis de las relaciones entre historia y psicología se introduce en el tema de las maravillas, la fantasía, los sueños y los temores. Como complemento a estas contribuciones y ejemplo de ese tipo de trabajos también podemos mencionar a Isabel Soler en El nudo y la esfera. El navegante como artífice del mundo moderno y el aporte de Juan Pérez de Tudela y Bueso Mirabilis in altis.

Queda mucho por hacer en el terreno de la historia de lo imaginario en el Perú, por lo que es necesario una mayor difusión de los aspectos teóricos y las referencias bibliográficas en ese campo. El refuerzo en la vocación interdisciplinaria de los historiadores también debe propiciar un mayor interés por estos temas y la presencia de una asignatura especial consolidaría dichos avances. Las relaciones con psicólogos, antropólogos y sociólogos permitirán una mayor soltura en el manejo de los instrumen- 
tos de análisis; no se debe olvidar también la necesidad que se tiene de un mayor conocimiento de la historia oral y su metodología. El estudio de las crisis en la historia del Perú también favorecerá el desarrollo de la historia de lo imaginario, pues es en ese contexto donde afloran manifestaciones de imaginario colectivo. La época contemporánea tampoco es ajena a esta tendencia, pues en otros contextos tenemos interesantes aportes que han ayudado a la comprensión de sus propios procesos históricos. El terreno está abierto a las contribuciones y esta tendencia de investigación ofrece no solo desafíos sino muchas satisfacciones intelectuales.

\section{REFERENCIAS BIBLIOGRÁFICAS}

Se señalan a continuación todas las obras mencionadas en el texto que representan contribuciones a la historia de lo imaginario, así como las de citas a pie de página.

BALTRUSAITIS, Jurgis

1983 La Edad Media fantástica. Madrid: Ediciones Cátedra.

BURGA, Manuel

1988 Nacimiento de una utopía. Muerte y resurrección de los Incas. Lima: Instituto de Apoyo Agrario.

BUSTO, José Antonio del

1974 Historia de los descubrimientos geográficos. Lima: Editorial Arica.

CERTAU, Michel de

1982 La fable mystique, 1 XVIe-XVIIe siècle. Paris: Gallimard.

1987 Histoire et psychanalyse entre science et fiction. Paris: Gallimard.

CURATOLA, Marco

1977 Mito y milenarismo en los Andes: Del Taqui Onqoy a Inkarrí. La visión de un pueblo invicto. Revista Allpanchis (10). Cusco.

DUBY, Georges

1976 Le Temps des cathedrals. L'Art et la Societé 980-1420. Paris: Gallimard. 
FEBVRE, Lucien

1959 El problema de la incredulidad en el siglo XVI. La religión de Rabelais. México: UTEHA.

FERRO, Marc

1980 Cine e Historia. Barcelona: Gustavo Gili.

FLORES GALINDO, Alberto

1988 Buscando un inca. Lima: Editorial Horizonte.

FOCILLON, H.

1938 Art d'Occident. Le Moyen Age roman et gothique. Paris: A. Colin.

FOUCAULT, Michel

1976 Storia della follia nell'Eta Classica. Milano: Rizzoli.

GISBERT, Teresa

2012 El paraíso de los Pájaros Parlantes. La imagen del otro en la cultura andina. La Paz: Plural editores.

GLAVE, Luis Miguel

1998 De Rosa y espinas. Economía, sociedad y mentalidades andinas. Siglo XVII. Lima: Instituto de Estudios Peruanos.

GRAF, Arturo

1991 El diablo. Barcelona: Montesinos.

HERNÁNDEZ, Max, y otros

1987 Entre el mito y la historia. Psicoanálisis y pasado andino. Lima: Ediciones Imago.

HOCQUENGHEM, Anne-Marie

1987 Iconografía mochica. Lima: Pontificia Universidad Católica del Perú, Fondo Editorial. Universidad Nacional San Cristóbal de Huamanga.

HUERTAS VALLEJOS, Lorenzo

1981 La religión en una sociedad rural andina. Ayacucho: UnNSCH. 
HUIZINGA, Johan

1965 El otoño de la Edad Media. Madrid: Revista de Occidente.

KAPPLER, Claude

1980 Monstres, Démons et Merveilles á la fin du Moyen Age. París: Payot.

KAPSOLI, Wilfredo

2010 Ayllus del Sol. Anarquismo y utopía andina. Lima: Asamblea Nacional de Rectores.

KAUFFMANN DOIG, Federico

1998 Ultratumba entre los antiguos peruanos. En: Homenaje al Dr. Aurelio Miro Quesada. Lima: Academia Peruana de la Lengua.

LE GOFF, Jackes

1981 La naissance du Purgatoire. Paris: Gallimard.

1983 Il meraviglioso e il quotidiano nell 'Occident Medievale. Bari: La Terza.

1985 Le imaginaire medieval. París: Gallimard.

LECOUTEUX, Claude

1986 Fantomes et revenants au Moyen Age. Paris: Imago.

1993 Les monstres dans la Pensée Medievale Européenne. Paris: Presses de l'Université de Paris-Sorbonne.

MANDROU, Robert

1979 Magistrati e streghe nella Francia del Seicento. Bari: Universale Laterza.

MILLONES, Luis, y otros

1990 El retorno de las huacas. Lima: IEP - SPP.

MILLONES, Luis y Wilfredo KAPSOLI

2001 La memoria de los ancestros. Lima: Editorial Universitaria, Universidad Ricardo Palma.

MILLONES, Luis

2008 Poder y religión en los Andes Centrales. Lima: Fondo Editorial del Congreso del Perú. 
MORIN, E.

1956 Le Cinéma ou l'Homme imaginaire. Essai d'anthropologie sociologique. Paris: Ed. De Minuit.

MUCHEMBLED, Robert

1991 La sorciere au village. XVe-XVIIIe siecle. Paris: Gallimard.

MUJICA PINILLA, Ramón

1992 Ángeles apócrifos en la América Virreinal. México: Fondo de Cultura económica.

PATLAGEAN, Evelyne

1978 “L'histoire de l>imaginaire”. En: La Nouvelle Histoire. París: RetzC.E.P.L.

PEASE G.Y., Franklin

1973 El Dios Creador andino. Lima: Mosca Azul.

PÉREZ DE TUDELA Y BUESO, Juan

1983 Myrabilis in altis. Madrid: C.S.I.C.

ROSAS LAURO, Claudia

2005 El miedo en el Perú. Lima: Pontificia Universidad Católitca Del Perú, Fondo Editorial.

ROSAS MOSCOSO, Fernando

1988 El Hombre y el Dominio de los Espacios: Mecanismos Oníricos y Temores en la Expansión Europea (Siglos XIII-XV). Lima: Universidad de Lima.

SOLER, Isabel

2003 El nudo y la esfera. El navegante como artífice del mundo moderno. Barcelona: Acantilado.

TENENTI, Alberto

1977 Il senso della morte e l'amore della vita nel Rinascimento. Torino: G. Einaudi. 
VERMEULE, Emily

1984 La muerte en la poesía y en el arte de Grecia. México: Fondo de Cultura Económica.

VERNANT, Jean Pierre

1983 Mito y Pensamiento en la Grecia Antigua. Barcelona: Ediciones Ariel.

VIDAL-NAQUET, Pierre

1968 Le chasseur noir et l'origine de l'ephebie athénienne. En: Annales E.S.C. (pp. 947-964).

VOVELLE, Michel

1989 Histoires figurales. Des monstres medievaux a Wonderwoman. Florence: USHER.

YAURI MONTERO, Marcos

2009 Simbolismo de las plantas alimenticias nativas en el imaginario andino. Lima: Universidad Ricardo Palma, Editorial Universitaria. 